\title{
Institutional Delivery Services Utilization and Associated Factors at Hetosa District, Ethiopia
}

\author{
Hailu Temesgen ${ }^{1, *}$, Alemayehu Worku, ${ }^{2, ~ *}$, Hailu Fekadu Demissie ${ }^{3, \text {, }}$, Mesfin Tafa Segni ${ }^{3, ~ *, ~}$ \\ Shimelis Adugna ${ }^{4, *}$, Roza Amdemichael ${ }^{5, *}$, Shimelis Mekit ${ }^{6, *}$ \\ ${ }^{1}$ Health Department, Arsi Zone, Assela, Ethiopia \\ ${ }^{2}$ Department of Public Health, Adis Ababa University, Addis Ababa, Ethiopia \\ ${ }^{3}$ Department of Public Health, Arsi University, Assela, Ethiopia \\ ${ }^{4}$ Department of Medical Laboratory, Arsi University, Assela, Ethiopia \\ ${ }^{5}$ Department of Midwifery, Arsi University, Assela, Ethiopia \\ ${ }^{6}$ Department of Pharmacy, Arsi University, Assela, Ethiopia

\section{Email address:} \\ Hailufekadu18@yahoo.com (H. F. Demissie), hailuoro@gmail.com (H. Temesgen),mesfintafa2011@gmail.co (M. Tafa), \\ shimeadu13@gmail.com (S. Adugna),rozket@gmail.com (R. Amdemichael), shimelis@gmail.com (S. Mekit) \\ ${ }^{*}$ Corresponding author
}

\section{To cite this article:}

Hailu Temesgen, Alemayehu Worku, Hailu Fekadu Demissie, Mesfin Tafa Segni, Shimelis Adugna, Roza Amdemichael, Shimelis Mekit. Institutional Delivery Services Utilization and Associated Factors at Hetosa District, Ethiopia. American Journal of Life Sciences. Vol. 8, No. 4, 2020, pp. 60-68. doi: 10.11648/j.ajls.20200804.13

Received: June 17, 2020; Accepted: August 5, 2020; Published: August 13, 2020

\begin{abstract}
Background: The proportion of births attended by skilled health personnel in Ethiopia is very low and the maternal mortality ratio currently is 676 per 100,000 live births. This study aimed at assessing level of institutional delivery service utilization and associated factors among mothers who gave birth during the last 12 months prior to the study in Hetosa district, Arsi zone Ethiopia. Methods: Community based cross sectional study design was conducted among 735 mothers who gave birth within last one year at Hetosa District in 2015. The collected data were entered into computer usingEpi-info version 3.5.1 and exported to SPSS version 20 software for analysis. Univariate, Bivariate and multivariate analysis were done. Significance level and association of variables was tested by using $95 \%$ confidence interval (C.I) and odd ratio and p-value less than 0.05 was taken as statistically significant. Result: Forty nine percent of the respondentsgave birth at health facilities and $98 \%$ delivered at public health facility. Out of those mothers who delivered at home, $36 \%$ were assisted by neighbor and the main reason for their home delivery was easy (precipitate) labor and very short duration which force mother to deliver at home $89 \%$ followed by transport problem (7.2\%). According to multivariate regression analysis mothers who reside in urban, did not live with her husbandand had one live birthwere more likely to give birth at health institution when compared to their counter parts. Conclusion and recommendation: This study revealed that institutional delivery was high as compared to some of the studies conducted on different parts of the country. Policy makers and health care planners need to recognize the factors hampering institutional delivery and work on improving the situation.
\end{abstract}

Keywords: Institutional Delivery, Utilization, Hetosa District

\section{Introduction}

Globally, there was an estimated 289,000 maternal deaths in 2013, yielding a maternal mortality rate (MMR) of 210 maternal deaths per 100,000 live births. Developing countries account for $99 \%$ of the global maternal death [1]. Maternal mortality is the highest by far in sub-Saharan Africa, where the lifetime risk of death from pregnancy-related conditions is 1 in 16, compared with 1 in 2800 in rich countries [2,3].

In Ethiopia, according to EDHS 2011 and 2016, there are 676 and 412 maternal deaths for every 100,000 live birth, respectively [4]. Maternal death is the most extreme consequence of poor maternal health outcomes. However, due to inadequate care during pregnancy and delivery or the 
first critical hours after birth, more than 30 million women in developing regions

Major causes of maternal deaths in Ethiopia are similar to most developing countries such as Infection, hemorrhage, obstructed lab our, abortion and hypertension in pregnancy $[3,7]$. At health facility level hemorrhage $(\mathrm{PPH})$ is responsible for $11 \%$ of all maternal deaths due to direct obstetric complications. The proportion deaths due to PPH that occurred in facilities is most likely due to the fact that over $90 \%$ of births take place at home, and women with PPH may not be arriving at health facility in time $[4,8]$.

Institutional delivery service utilization is one of the key and proven interventions to reduce maternal death. It ensures safe birth, reduce both actual and potential complications and maternal death and increase the survival of most mothers and newborns. But most deliveries in developing countries occur at home without skilled birth attendants.

Socio-economic, socio-demographic, ante natal care attendance and health services related factors were associated with institutional delivery service utilization in studies conducted in Asia including African and Ethiopia. Not only maternal variables, husband personal, socio demographic and wealth therefore, in recognition of the national burden of maternal mortality and the urgency to achieve the Millennium Development Goal 5 (MDG-5), the government of Ethiopia is committed to improve maternal health with a target of reducing maternal mortality ratio (MMR) to 267/100,000 live births through multi-pronged approaches including provision of free delivery service [5, 9].

In despite of this institutional delivery service use was low and majority of women in Ethiopia have been giving birth at home $[6,10]$. Hence; it is important to provide evidences based research on important determinants of institutional delivery service use. Therefore, this study is intended to assess institutional delivery service utilization and associated factors among mothers in Hetosa district, Arsi zone, and Oromia region.

\section{Methods}

\subsection{Study Area and Period}

This study was conducted at Hetosa Woreda in Arsi Zone, Oromia Regional State, South East Ethiopia in 2017. Iteya is the capital city of the Woreda located $150 \mathrm{~km}$ from Addis Ababa the capital city of Ethiopia. Organized into 23 rural and 3 urban kebeles, the district has 4 functional public health centers, one higher private clinics, and 23 rural and three urban health posts with assigned two female health extension workers per each health post $(52$, HEWs) and have 68 health professional workers (10 health officers, $7 \mathrm{BSC}$ nurse and 10 midwifes) with $75 \%$ of potential health coverage and with elevation of 2215 meters above sea level. Total population was 151, 859 $($ male $=77,448(51 \%)$, and female $=74,411(49 \%)$ ), women child bearing age 33, 409 and about 31, 637 total households [10].

\subsection{Study Design}

A community-based cross-sectional study design was used.

\subsection{Sources Population}

All mothers who gave birth within last one year in Hetosa woreda.

\subsection{Inclusion Criteria}

All women whose age is between 15-49 years and who gave birth in the past 12 months irrespective of birth outcome.

\subsection{Exclusion Criteria}

Mother who were critically sick and cannot communicate or listen and who did not want to participate in this study was excluded.

\subsection{Sample Size}

The Sample size was calculated using double Epi info software with the following assumptions; at 95\% CI with power of $80 \%$, proportion of institutional delivery among higher level of education was $24.5 \%$ and odds ratio (OR) 2 [11], Odds Ratio educate to un educated 1:1, design effect of 2 and non-response rate $10 \%$. Then the final sample size was 735 .

\subsection{Sampling Procedures}

Multi stage sampling technique was used to select the study units. Hetosa Woreda has 26 total kebeles (the smallest administrative unit), 31, 637 house hold and 79 gote (sub division of kebele), Eight Kebeles were selected by using simple random sampling (lottery) method (Figure 1).

The sample size was distributed to eight kebeles proportional to the size of their population. Households with women gave birth past 12 months prior to study period were selected using simple random sampling based on the sampling frame obtained from health extension worker of selected kebeles collected by community health information system (CHIS).

The sampling intervals of household determined by dividing total number of house hold to sample size for each kebele. If the houses were closed or the mothers were not present at the time of data collection, three times daily visits supported by volunteerwho selected from kebele were made until we communicated them throughout the data collection period. The next houses were considered in place of the houses which could not be accessed for collecting mothers' data regarding institutional delivery service utilization. If there was more than one mother within the same household lottery method was used to select the one to be included in the sample.

\subsection{Operational Definition}

Utilization of Institutional delivery: is giving the current birth of a baby at public or private health facility except 
Health Post (if delivery conducted by HEWs).

\begin{tabular}{|c|c|c|c|c|c|c|c|}
\hline \multicolumn{8}{|c|}{ Hetosa woreda (26 kebeles) } \\
\hline \multicolumn{8}{|c|}{ Simple Random Sampling } \\
\hline \multicolumn{8}{|c|}{8 Kebeles $(31 \%)$ selected } \\
\hline $\begin{array}{l}\text { Hate Handode } \\
1303 \\
\text { house hold }\end{array}$ & $\begin{array}{l}\text { Seroanketo } \\
1468 \\
\text { House hold }\end{array}$ & $\begin{array}{l}\text { DeyaDebeso } \\
1269 \\
\text { house hold }\end{array}$ & $\begin{array}{l}\text { SHakiSharara } \\
1476 \\
\text { house hold }\end{array}$ & $\begin{array}{l}\text { Eteya } \\
1205 \\
\text { house hold }\end{array}$ & $\begin{array}{l}\text { DaweGuticha } \\
1100 \\
\text { house hold }\end{array}$ & $\begin{array}{l}\text { Boneyaedo } \\
1949 \\
\text { house hold }\end{array}$ & $\begin{array}{l}\text { Tedo } \\
\text { Leman1068 } \\
\text { house hold }\end{array}$ \\
\hline \multicolumn{8}{|c|}{ Simple Random Sampling } \\
\hline 2 gote & 2 gote & 2 gote & 2 gote & 3 gote & 2 gote & 2 gote & 2 gote \\
\hline \multicolumn{8}{|c|}{ Simple Random Sampling } \\
\hline $\begin{array}{l}88 \\
\text { Mothers }\end{array}$ & $\begin{array}{l}100 \\
\text { Mothers }\end{array}$ & $\begin{array}{l}86 \\
\text { mothers }\end{array}$ & $\begin{array}{l}100 \\
\text { Mothers }\end{array}$ & $\begin{array}{l}82 \\
\text { Mothers }\end{array}$ & $\begin{array}{l}75 \\
\text { Mothers }\end{array}$ & $\begin{array}{l}132 \\
\text { mothers }\end{array}$ & $\begin{array}{l}72 \\
\text { Mothers }\end{array}$ \\
\hline
\end{tabular}

Selected mothers for the study

$$
\text { Total sample size }-735
$$

Figure 1. Schematic presentation of sampling procedure, 2015.

\subsection{Data Collection Procedures and Data Quality Control}

Structured and pre-test questionnaire developed based on the literatures were prepared first in English and then translated into Afan Oromo the local language, then retranslated back from Afan Oromo to English by another person to insure the consistency of the tool. Diploma graduate female health worker wereparticipated to conduct the face to face interviews through house to house visiting and supervised by two degree holders. Training was given forboth data collectors and supervisors before the actual data collection regarding the aim of study, data collection tool and procedures. During data collection the supervisors were received questionnaires from data collectors and review for completeness, accuracy, and consistency on daily base. Correction measures were taken by discussing with the research team, generally data quality was ensured by coding during data collection if codes were given to the questionnaires during data collection so that any identified problems were solved using the codes.

\subsection{Data Management and Analysis Procedures}

The collected data were entered into computer usingEpiinfo version 3.5.1 software. After the entrance and completeness of all data, cleaning was done. Finally, the data was exported to SPSS version 20 for analysis. Both the descriptive and Bivariate/multivariate logistic regression analysis was performed. Descriptive analyses were done by using frequency, mean, median, standard deviation, and percentages. Crude logistic regression was used to see relationship between one independent variable with outcome at time and adjust logistic regression was used to see relationship between many independent variables with outcome variable after controlling confounding factors. Significance level and association of variables were tested by using 95\% confidence interval (C.I) and odd ratio and pvalue less than 0.05 was taken as statistically significant.

\subsection{Ethical Consideration}

Ethical clearance was obtained from College of Health
Science, Arsi University and a supportive letter was obtained from Arsi zonal health department and given for Hetosa woreda health office then to kebeles. Oral informed consent was obtained from respondents after explaining the purpose and benefit of study. To ensure the confidentiality of respondents their names were not written on the questionnaire and to keep privacy of respondents the interview was implemented separately without including anyone except interviewer.

\section{Result}

\subsection{Socio-Demographic Characteristics of the Study Participants}

A total of 735 mothers who gave birth in the last 12 months prior to this study were interviewed and with a response rate of $100 \%$. Of the respondents, $652(88.8 \%)$ were from rural. The mean age of the respondents was $25.78 \pm 5.25$ SD. Thirty-eight percent (281) mothers were in the age range of 25-29 years. Majorities (96\%) were married and $523(71 \%)$ mothers attended formal education. With respect to occupation of respondents 684 (93\%) of them were housewives. With regard to religion, $500(68 \%)$ were Muslim and $222(30 \%)$ were orthodox. Oromo 693 (94\%) was the predominant ethnic group. As to the husband's occupational status, the majority $80 \%$ (590) were farmers. Economically, 257 (35\%) of the households had monthly income of between 501-1000 ETB and 208 (28\%) less than 500 ETB monthly income based on quartile classification (Table 1).

Table 1. Socio-Demographic characteristics of the respondent Hetosa woreda, 2015.

\begin{tabular}{lll}
\hline Variable & Frequency & Percent \\
\hline Age & & \\
$15-19$ & 57 & 7.8 \\
$20-24$ & 240 & 32.6 \\
$25-29$ & 329 & 44.8 \\
$30-34$ & 109 & 14.8 \\
Residence & & \\
Urban & 82 & 11.0 \\
\hline
\end{tabular}




\begin{tabular}{lll}
\hline Variable & Frequency & Percent \\
\hline Rural & 653 & 89.0 \\
Marital status & & \\
Single & 17 & 2.3 \\
Married & 707 & 96.2 \\
Separated & 7 & 1.0 \\
Divorced & 4 & 0.5 \\
Live with husband & & \\
Yes & 643 & 87.5 \\
No & 92 & 12.5 \\
Religion & & \\
Orthodox & 222 & 30.2 \\
Protestant & 13 & 1.8 \\
Muslim & 500 & 68 \\
Ethnicity & & \\
Amhara & 35 & 4.8 \\
Oromo & 693 & 94.3 \\
Others & 7 & 0.9 \\
Education status of mother & & \\
No formal education & 212 & 28.8 \\
Can read and write & 185 & 87.3 \\
Primary (1-8) & 412 & 78.8 \\
Secondary & 102 & 19.5 \\
Tertiary & 9 & 1.7 \\
Occupation of mother & & 93.2 \\
Unemployed & 685 & 4.9 \\
Self-employed & 36 & 1.9 \\
Government employ & 14 & \\
Educational status of husband & & \\
\hline & & \\
\hline
\end{tabular}

\begin{tabular}{lll}
\hline Variable & Frequency & Percent \\
\hline No formal education & 98 & 13 \\
Can read and write & 28 & 4 \\
Primary (1-8) & 398 & 54 \\
Secondary & 189 & 26 \\
Tertiary & 22 & 3 \\
Occupation of husband & & \\
Unemployed & 14 & 1.94 \\
Self-employed & 664 & 92.22 \\
Government employee & 42 & 5.83 \\
\hline
\end{tabular}

\subsection{Obstetric History of the Respondents}

Forty three percent of mothers were parity two to four and 177 (24\%) of them were parity five and above. Fifty four percent mothers became pregnant before the age of 20 years. The minimum and maximum ages at first pregnancy were 14 and 34 years with mean age of 19.5 years and \pm 3.3 SD. About Ninety one percent of the respondents had ANCfollow up during recent delivery, to know her health status was the most $(42.6 \%)$ commonly raised reason. Out of Six hundred sixty eight mothers who attended ANC service, 506 (75.7\%) of them received information on where to deliver and delivery complication. Among the respondent who did not visit health facility $37(50 \%)$ of them reported that, their main reason was no health problem during labour $(50 \%)$ [Table 2].

Table 2. Obstetric History of the respondents Hetosaworeda, 2015.

\begin{tabular}{|c|c|c|}
\hline Variable & Frequency & Percent \\
\hline \multicolumn{3}{|l|}{ Parity } \\
\hline $0-1$ & 241 & 32.8 \\
\hline $2-4$ & 317 & 43.1 \\
\hline 5 and above & 177 & 24.1 \\
\hline \multicolumn{3}{|l|}{ Age at first delivery } \\
\hline$<15$ & 46 & 6.3 \\
\hline $15-19$ & 353 & 48 \\
\hline $20-24$ & 267 & 36.3 \\
\hline $25+$ & 69 & 9.4 \\
\hline \multicolumn{3}{|l|}{ Number of live births } \\
\hline 1 & 255 & 34.5 \\
\hline $2-4$ & 329 & 44.8 \\
\hline $5+$ & 151 & 20.5 \\
\hline \multicolumn{3}{|l|}{ Place of last 12 month delivery } \\
\hline Health facility & 360 & 49 \\
\hline Home & 375 & 51 \\
\hline \multicolumn{3}{|c|}{ ANC attending for your recent delivery } \\
\hline Yes & 668 & 90.9 \\
\hline No & 67 & 9.1 \\
\hline \multicolumn{3}{|c|}{ No of Frequency for ANC (668) } \\
\hline 1 & 51 & 7.6 \\
\hline $2-3$ & 345 & 51.6 \\
\hline $4+$ & 272 & 40.8 \\
\hline \multicolumn{3}{|c|}{ The reasons for ANC visit, multiple response is possible.(980) } \\
\hline Were sick & 291 & 29.7 \\
\hline Health facility near & 32 & 3.3 \\
\hline Good health facility service & 35 & 3.6 \\
\hline Husband encouraged & 12 & 1.2 \\
\hline To know my health status & 418 & 42.6 \\
\hline To know fetus status & 191 & 19.5 \\
\hline Other & 1 & 0.1 \\
\hline
\end{tabular}




\begin{tabular}{lll}
\hline Variable & Frequency & Percent \\
\hline Yes & 622 & 93.1 \\
No & 46 & 6.9 \\
Receiving information about delivery complications & & 75.7 \\
Yes & 506 & 24.3 \\
No & 162 & 43 \\
Types of information received during ANC & & 5.6 \\
On severe vaginal bleeding & 356 & 2.8 \\
Severe head ache & 46 & 5 \\
Marked fast weight gain & 23 & 22.7 \\
Fetal movement cessation & 42 & 20.8 \\
Prolonged labor & 188 & 0.2 \\
Retained placenta & 172 & 50 \\
Others & 1 & 9.5 \\
The reason for not conducted ANC follow up & & 6.7 \\
No health problem & 37 & 1.4 \\
Because of work load & 7 & 13.5 \\
Health facility far (distance) & 5 & 4 \\
Husband refused & 1 & 14.8 \\
Afraid fee & 10 & \\
Poor handling of health workers & 3 & \\
Feel shame & 11 & \\
\hline
\end{tabular}

\subsection{Access to Information and Health Facility}

Eighty one percent of respondentsever had health education on maternal health. Fifty nine percent pointed out health extension workers as the main source of information on maternal health whereas the least source wastraditional birth attendants. Almost all (99.6\%) of the respondentshad access to any health facility in their kebele. Concerning the time they travelled on foot to reach the nearby health facility $652(89 \%)$ of them said less than one hour, $83(11 \%)$ said greater than one hour (Table 3).

Table 3. Respondents access to information and health facility, Hetosa district, 2015.

\begin{tabular}{lll}
\hline Variable & Frequency & Percent \\
\hline Ever had health education on maternal health & 138 & 18.8 \\
No & 597 & 81.2 \\
Yes & & \\
By whom had, health education on maternal health & 436 & 59.3 \\
Health extension workers & 4 & 0.5 \\
Traditional birth attendants & 212 & 28.8 \\
Health workers & 95 & 12.9 \\
Through radio & 65 & 8.8 \\
Through television & & \\
Access to health facility in kebele & 732 & 99.6 \\
Yes & 3 & 0.4 \\
No & 652 & 88.7 \\
Time taken to visit health facility & 83 & 11.3 \\
$\leq 1$ hour & & \\
$>$ 1hour & &
\end{tabular}

\subsection{Awareness and Attitude Related to Institutional Delivery of the Respondent}

Regarding awareness of mothers' place of delivery, the majority $(93.6 \%)$ of them pointed out that giving delivery at health facility was better than giving birth at home. The reasons why they preferred to deliver recently at health institutions were because if delivery was conducted at health facilitythere would be no bleeding 301 (22.7\%), saves mother life $288(21.7 \%)$ and other reasons as mentioned in table 4 . Regarding mothers awareness on their susceptibility to pregnancy and delivery complications, Twenty six (224) almost nearly half of the respondents reported that every mother including herself is susceptible to pregnancy and delivery complications while the rest $25.3 \%$ (213) $21.7 \%$
(101) $24.7 \%$ (208) and $23.4 \%$ (197) said that primi-gravida, mothers with multiple pregnancy, mothers with other medical problems and multi-gravid mothers are susceptible to pregnancy and delivery complications, respectively.

Concerning awareness to the occurrence of complication during delivery 418 (34.5\%), 384 (31.8\%), 361 (29.8\%), and $47(3.9 \%)$ of respondents mentioned that severe hemorrhage, retained placenta lasting more than 30 minutes, prolonged labor lasting more than 12 hours, and loss of consciousness are labour complications that can occur during child birth, respectively.

Regarding attitude of the respondent toward institutional delivery, respondents were asked questions related to their attitude on institutional delivery service. More than three quarters of the respondents $78 \%$ hadpositive attitude 
regarding ANC and delivery services (Table 4).

Table 4. Awareness and attitude related to institutional delivery of the respondent Hetosa district, 2015.

\begin{tabular}{|c|c|c|}
\hline Variable & Frequency & Percent \\
\hline \multicolumn{3}{|c|}{ Awareness about difference between giving birth at home or health facility } \\
\hline No & 17 & 2.3 \\
\hline Yes & 688 & 93.6 \\
\hline I don't know & 30 & 4.1 \\
\hline \multicolumn{3}{|l|}{ If yes, health facility is better in what reason } \\
\hline Good delivery service & 131 & 9.9 \\
\hline Save mother life & 288 & 21.7 \\
\hline Decrease risk of bleeding & 301 & 22.7 \\
\hline Decrease complication of retained placenta & 219 & 16.5 \\
\hline Save child life & 230 & 17.4 \\
\hline Shorter labor & 157 & 11.8 \\
\hline \multicolumn{3}{|l|}{ If home delivery is better, what is the reason } \\
\hline No need of transport & 2 & 11.7 \\
\hline No cost & 3 & 17.6 \\
\hline No bleeding & 1 & 5.9 \\
\hline There is privacy & 5 & 29.4 \\
\hline Others & 6 & 35.3 \\
\hline \multicolumn{3}{|c|}{ Mothers susceptible for pregnancy and delivery complications } \\
\hline Every mother including myself & 224 & 26.6 \\
\hline Primi-mothers & 213 & 25.3 \\
\hline Multi gravid mothers & 208 & 24.7 \\
\hline Mothers with other medical problems & 197 & 23.4 \\
\hline \multicolumn{3}{|l|}{ Complications that can occur during delivery } \\
\hline Severe hemorrhage & 418 & 34.5 \\
\hline Retained placenta & 384 & 31.8 \\
\hline Prolonged lab our & 361 & 29.8 \\
\hline Loss of consciousness & 47 & 3.9 \\
\hline \multicolumn{3}{|l|}{ Whom do you prefer to assist you next deliver } \\
\hline Health worker & 719 & 97.8 \\
\hline Other (mother, mother in law, TBA and neighbor) & 16 & 2.2 \\
\hline \multicolumn{3}{|l|}{ Over all Attitude of the Mother on delivery services } \\
\hline Favorable & 573 & $(78 \%)$ \\
\hline Unfavorable & 162 & $(22 \%)$ \\
\hline
\end{tabular}

\subsection{Institutional Delivery Service Utilization}

Of the respondents, 360 (49\%) (95\% CI: 47.05-50.95) of them gave birth at health facilitiesand 375 (51\%) delivered at home. Out of those mothers who delivered at home, 135 $(36 \%)$ were assisted by Neighbor and the main reason for their home delivery was easy (precipitate) or uncomplicated labor $334(89 \%)$ followed by transport problem (7.2\%). Among the respondents who deliver at health institution, 356 $(98.9 \%)$ of them deliver at public health facility and decision making on the choice of place of delivery was made by themselves majorly 59.4\% (Table 5).

Table 5. Institutional delivery service utilization, Hetosa Woreda, 2015.

\begin{tabular}{lll}
\hline Variable & Frequency & Percent \\
\hline Place of last 12 month delivery & 360 & 49 \\
Health facility & 375 & 51 \\
Home & & 89.1 \\
Reasons for home delivery (375) & 334 & 7.2 \\
Easy labour (Precipitated labour) & 27 & 3.7 \\
Transport problem & 14 & 10.7 \\
Other & & 25.3 \\
Assistance at home delivery (375) & 40 & 27.2 \\
Mother & 95 & 36 \\
Mother in law & 102 & 0.8 \\
TBA & 135 & 24.7 \\
Neighbor & 3 & 61.7 \\
Other specify & & 1.7 \\
Assistance at health facility delivery (360) & 89 & 12 \\
Nurse & 222 & \\
Midwife & 6 & 43 \\
Health officer & & \\
Doctor & & \\
Types of health facility they attended delivery & & \\
\hline
\end{tabular}




\begin{tabular}{lll}
\hline Variable & Frequency & Percent \\
\hline Public & 356 & 98.9 \\
Private & 4 & 1.1 \\
The reason to give birth at facility for the recent baby & & 41 \\
Were sick & 174 & 4.2 \\
No fee & 18 & 3.3 \\
Health facilities near & 14 & 8 \\
Good services & 34 & 42.4 \\
Received health educations & 180 & 1.1 \\
Others specify. & 5 & \\
Decision maker on choice of place of delivery & & 59.4 \\
Myself & 611 & 29 \\
My husband & 299 & 7.6 \\
Health workers & 78 & 4 \\
\hline
\end{tabular}

\subsection{Determinants of Utilization of Institutional Delivery}

In the bivariate logistic regression residence, religion, receiving information about institutional delivery parity, living with husband, ANC follow up, distance to health facility, monthly income and age at first delivery were significantly associated variables. In multivariable logistic analysis for controlling possible confounding effect; residence, religion, parity and living in the same house with partner show significant association with utilizations of

institutional delivery.

Mothers who reside in urban were more than 10.9 times more likely to utilize health facility for delivery than those who live in rural area $A O R=10.9,(95 \% \mathrm{CI}=5-4.4)$. Similarly mothers who did not live with her husband was 2.4 times likely to use institutional delivery than mothers who live with her husband ( $\mathrm{AOR}=2.4 \mathrm{CI} ; 1.4,4.4)$. On the other hand those respondents who had had one live births were almost more than three times likely to give birth at health institution when compared to those who had had four or more

Table 6. Determinants of utilization of institutional delivery Hetosa Woreda, 2015.

\begin{tabular}{|c|c|c|c|c|}
\hline \multirow{2}{*}{ Variable } & \multicolumn{2}{|c|}{ Institutional Delivery service utilization } & \multirow{2}{*}{ COR $(95 \%$ CI) } & \multirow{2}{*}{ AOR (95\% CI) } \\
\hline & Yes & No & & \\
\hline \multicolumn{5}{|l|}{ Residence } \\
\hline Urban & 74 & 8 & $11.9(5.625 .0)$ & $10.9(5.4,24.4)^{*}$ \\
\hline Rural & 286 & 367 & 1 & 1 \\
\hline \multicolumn{5}{|l|}{ Age } \\
\hline $15-25$ & 166 & 220 & $2.3(1.5-3.7)$ & $1.3(0.2-7.5)$ \\
\hline $26-35$ & 174 & 136 & $1.7(1.1-2.5)$ & $0.5(0.56-2.3)$ \\
\hline$>35$ & 20 & 19 & 1 & 1 \\
\hline \multicolumn{5}{|c|}{ Having ANC follow up } \\
\hline Yes & 341 & 327 & 1 & 1 \\
\hline No & 19 & 48 & $0.4(0.23,0.7)$ & --- \\
\hline \multicolumn{5}{|c|}{ Live with husband } \\
\hline Yes & 34 & 341 & $1.5(0.59,3.83)$ & 1 \\
\hline No & 58 & 301 & $1.97(1.2,3.3)$ & $2.4(1.4,4.4)^{*}$ \\
\hline \multicolumn{5}{|l|}{ Religion } \\
\hline Orthodox & 128 & 94 & $1.66(1.2,2.3)$ & $2(0.46,1.86)$ \\
\hline Protestant & 10 & 3 & $3.7(1,13.9)$ & 1 \\
\hline Muslim & 222 & 278 & 1 & \\
\hline \multicolumn{5}{|l|}{ Parity } \\
\hline $0-1$ & 78 & 163 & $3.4(2.2-5.1)$ & $2.96(1.87,4.68)^{*}$ \\
\hline $2-4$ & 173 & 144 & $1.3(0.9-1.9)$ & $1.2(0.8,1.8)$ \\
\hline 5 and above & 109 & 66 & 1 & 1 \\
\hline \multicolumn{5}{|c|}{ Distance of health facility } \\
\hline$\leq 1$ hour & 175 & 91 & $2.95(2.2,5.8)$ & $0.5(0.78-3.6)$ \\
\hline$>1$ hour & 185 & 284 & 1 & 1 \\
\hline
\end{tabular}

$* *$ significant at $\mathrm{p}$ - value $<0.05$

ove $\mathrm{AOR}=2.96,(95 \% \mathrm{CI}=1.87-4.68)$. (Table 6)

\section{Discussion}

This study attempted to identify the degree of skilled delivery service utilization and associated factors among mothers who gave birth in the last 12 months prior to the study in Hetosa District. The study showed that institutional delivery service utilization was (49\%) in the District and most of mothers $(51 \%)$ gave birth at home. The study was consistent with other studies conducted in Ethiopia previously at Woldia Woreda $(48.3 \%)$ and Goba woreda (47\%) [12-13]. However, it is higher as compared to similar community based studies conducted in Dodota Woreda, 
Sekela District, and Munesa Woreda, South East Ethiopia, where the proportion of women who gave birth at health facilities was, only $18.2 \%, 12.3 \%, 12.1 \%$ respectively [1416]. This discrepancy could be due to the time gap between these studies, difference in study settings and there might have been improvements in accessibility and utilization of health institution delivery service during the current study. It was less compared with findings from a study conducted in Bahirdar town which was $(78.8 \%)$. The great difference of this study is partially explained by the fact that this study is done in rural setting and that of Bahirdar is in town where health facility is nearly available and communities awareness about institutional delivery is very high. In addition to this, mothers in urban area could be autonomous in making decision, have good knowledge of pregnancy and delivery complications, and better access to information than rural mothers [17].

Institutional delivery was influenced by place of residence. Women residing in urban are about 11 times more likely to deliver in health care facility than rural women. This finding is in line with other studies done in our country [18]. This indicates the difference in access especially in terms of physical distance which is important for service utilization. If health facilities are not in close proximity or in walking distance, rural mothers are less likely to afford transportation cost. In many instances even if they can afford to pay the transportation fare, the vehicle may not be available at the time they need it.

Parity appears commonly as a major factor responsible for the utilization of ANC and institutional delivery. Although studies from Ethiopia [19] and elsewhere in Africa [20] have shown an inverse relationship between parity and the use of ANC services, The present study revealed that women having less than two children were more likely to use institutional delivery. This result was consistent with other national studies in which the probability of giving birth at health facilities decreases for women with five or more births [19]. One reason for this relationship could be the limited access to resources and time constraints related to child care and household activities. Another likely reason is that women with more children perceive delivery as a normal process and develop the confidence to give birth at home.

Similar to the findings of various studies in the country, religion emerged as a predictor for maternal service utilization [20, 21]. In our study Orthodox Christians followers were more likely to utilize the service than other religions (protestant, catholic and Muslims). As to how religion influences maternal health service utilization needs further studies to ascertain. However, one of the assumptions is that priests in orthodox Christians may teach their followers to use institutional delivery than other religions.

Unlike other study mothers who do not attended anc follow up more utilized institutional delivery service than those mothers attend anc in this case anc services cannotprovide opportunities for health workers to promote a specific place of delivery or give women information on the status of their pregnancy which in turn alerts them to decide where to deliver.

Majority of mothers preferred home delivery. The most common reasons for home delivery were easy labor, transport problem, far distance from health facility, poor service, afraid user fee, feel shame and husband refused. Similar study from Arsi Zone revealed that the main reasons for mothers to prefer home delivery was short labor 54.8\% [19]. Another study in North westidentified that the main reasons for home delivery were smooth and short labor $(42 \%)$, need to be attended with relatives during labor (44.7\%), trusting traditional birth attendants and cultural belief (55.3\%) [15].

This study showed that mothers who delivered at home had faced birth complications. Mothers who delivered at home reported complications such as severe hemorrhage $(34.5 \%)$ retained placenta $(31.8 \%)$, prolonged labor $(29.8 \%)$, and loss of consciousness (3.9\%). This finding is similar with the result reported from North Woldia, which revealed that $27.3 \%, 247.3 \%$ and $39.4 \%$ of mothers who gave birth at home had excessive vaginal bleeding, prolonged labor and retained placenta respectively $[15,12]$.

In summary, the above mentioned points indicate that place of residence, long distance of health facility, transport problem, notliving in the same home with partner, number of delivery (parity) and ANC follow up were major determinant barriers for mothers' utilization of institutional delivery.

Limitation of the study

One of the limitations of the study was lack of complementing with qualitative study and the other is the nature of the study beingcross sectional study design makes it difficult to determine the direction of causality.

Conclusion

Institutional delivery is high in study area compared to previous report, but still low compared to national plan. Place of residence living separately with her husband, long distance travel, number of parity and ANC follow up was major factor determine institutional delivery in this study

It is recommended that, Information on the complications of pregnancy and delivery and on the importance of using either the institutional delivery service, or skilled midwifery assistance in the home, at every childbirth should be given to every mother who came to health facility in general and at ANC visits in particular. It is also important increasing girls' enrollment in educations. Besides giving technical and material support Non-Governmental organization should have to work on programs of institutional delivery service in order to scale up institutional delivery service utilization.

\section{Competing Interest}

The authors declare that they have no competing interests.

\section{Acknowledgements}

We would like to express our gratitude to KOICA for financial support. We would like also to thank Hetosa woreda health office, for providing the background information about 
the study area. Moreover, we would like to acknowledge all data collectors, supervisors and study participants.

\section{References}

[1] A. Adegoke and N. van den Broek, "Skilled birth attendancelessons learnt," BJOG: An International Journal of Obstetrics \& Gynaecology, vol. 116, no. 1, pp. 33-40, 2009.

[2] D. Ohuwole, "An overview of the maternal and newborn health situation in the African region, in African health monitory," A magazine of WHO Regional Office for Africa, vol. 5, pp. 2-4, 2004.

[3] C. S. Agency and O. R. C. Macro, Ethiopia Demographic and Health Survey 2005, Central Statistical Agency, ORC Macro, Addis Ababa, Ethiopia, and Calverton Maryland, USA, 2006.

[4] CSA and ICF International Calverton, Ethiopia Demographic and Health Survey, CSA and ICF, Addis Ababa, Ethiopia, 2016.

[5] Hogan MC, Kyle J, Mohsen N, Stephanie Y, Mengru W, Susanna M, Alan D, Rafael L, Christopher JL. Maternal Mortality for 181 countries, 1980-2008: A systematic analysis of progress towards MDG 5. Lancet. 2010; 375 (9726): 16091623.

[6] FMOH, UNICEF, UNFPA, WHO and AMDD. National Baseline Assessment for Emergency Obstetric \& Newborn Care in Ethiopia. 2008. p. 18.

[7] US Global Health Policy, the U. S. Government and Global Maternal, Newborn \& Child Health. 2010.

[8] United Nations. Millennium Development Goals Report., New York; 2008. pp. 24-25.

[9] Central Statistical Agency [Ethiopia]. 2014. Ethiopia Mini Demographic and Health Survey 2014. Addis Ababa, Ethiopia.

[10] Hetosa woreda Health office Report 2014.

[11] Central Statistical Agency: Ethiopia Demographic and Health Survey, Preliminary Report, 2011. Ethiopia: Central Statistical Agency Addis Ababa; 2011.
[12] Worku Awoke, JemalMuhammed, GedefawAbeje. Institutional Delivery Service Utilization in Woldia, Ethiopia, Science Journal of Public Health. Vol. 1, No. 1, 2013, pp. 1823.

[13] Daniel BogaleOdo, DesalegnMarkosShifti. Institutional Delivery Service Utilization and Associated Factors among Child Bearing Age Women in Goba Woreda, Ethiopia. Journal of Gynecology and Obstetrics. Vol. 2, No. 4, 2014, pp. 63-70. doi: $10.11648 /$ j.jgo.20140204.14

[14] Amano A, Gebeyehu A, and Birhanu Z: Institutional delivery service utilization in Munesa Woreda, South East Ethiopia: a community based cross-sectional study. BMC Pregnancy and Childbirth, 2012; 12: p. 105.

[15] Teferra A. S, Alemu F. M, and Woldeyohannes S. M: Institutional delivery service utilization and associated factors among mothers who gave birth in the last 12 months in Sekela District, North West of Ethiopia: A community- based cross sectional study. BMC Pregnancy and Childbirth, 2012: 12 (74).

[16] Fikre AA, Demissie M: Prevalence of institutional delivery and associated factors in Dodota Woreda (district), Oromia Regional State, Ethiopia. Reprod Health 2012, 9: 33.

[17] Abebe F, Berhane Y, Girma B. Factors associated with home delivery in Bahirdar, Ethiopia: A case control study. BMC research notes. 2012; 5 (1): 653.

[18] Tsegay Y, Gebrehiwot T, Goicolea I: Determinants of antenatal and delivery care utilization in Tigray region. Ethiopia: a cross-sectional study. Int J Equity Health 2013, 12: 30 .

[19] Abera M, Belachew T. Predictors of safe delivery service utilization in Arsi Zone, South-East Ethiopia. Ethiopian journal of health sciences. 2011; 21 (3).

[20] Births in a Health Facility -Inequalities among the Ethiopian Women: Results from Repeated National Surveys.

[21] Shiferaw S, Spigt M, Godefrooij M, Milkman Y, Tekie M. Why do women prefer home births in Ethiopia? BMC Pregnancy and Childbirth. 2013; 13 (1): 5. 